\title{
KAJIAN KRITIS TERHADAP PESERTA LOMBA FLS2N CABANG TARI TINGKAT SMP TAHUN 2019 DI PROVINSI SUMATERA BARAT
}

\author{
Venny Rosalina, Fabio Yuda \\ Jurusan Sendratasik, FBS Universitas Negeri Padang \\ Email: vennyrosalina91@gmail.com, fabioyuda@gmail.com, No. Hp: 085220087221
}

\begin{abstract}
FLS2N is one of the most prestigious competency events in the West Sumatra region. The event provided a platform to continue to hone creativity and develop West Sumatra typical dances. Traditional Minangkabau values are one of the creative sources in packaging the dances that are presented in the competition stems at FLS2N. This study aims to analyze the extent to which the development of dance offerings in dance competition participants in West Sumatra Province. The focus of this research is the winners of the junior high school dance branch in 2019 in West Sumatra Province. This research is a qualitative research with a case study approach, with data collected through direct observation and interview techniques. The results of the study show that seen from critical fist, the dance performances of the winners of the competition at the West Sumatra Province level in 2019 still use motion patterns that tend to repeat old styles and forms. That is, choreologically, it tends not to be well developed. Meanwhile, there is still a tendency for many dance numbers to give less space to female dancers. It is an unfortunate fact that considering history shows that in fact female choreographers were the developers of contemporary Minangkabau dance.
\end{abstract}

Keywords: FLS2N, Minangkabau Dance, Critical Studies, Choreology, Minangkabau.

\begin{abstract}
ABSTRAK
FLS2N Cabang Tari adalah salah satu ajang kompetensi yang bergensi di wilayah Sumatera Barat. Acara tersebut memberikan sebuah wadah untuk terus mengasah kreativitas dan mengembangkan tarian-tarian khas Sumatera Barat. Nilainilai tradisional Minangkabau merupakan salah satu sumber kreatif dalam mengemas tari-tari yang disajikan pada tangkai lomba di FLS2N. Penelitian ini bertujuan untuk menganalisis sejauh mana perkembangan sajian tari pada peserta lomba cabang tari di Provinsi Sumatera Barat. Fokus penelitian ini adalah para pemenang dari cabang tari tingkat SMP pada Tahun 2019 di Provinsi Sumatera Barat. Penelitian ini merupakan penelitian kualitatif dengan pendekatan studi kasus, denngan data yang dikumpulkan melalui Teknik pengamatan langsung dan wawancara. Hasil penelitian menunjukkan bahwa dilihat dari tinjuan kritis, maka sajian tari para pemenang lomba di tingkat Provinsi Sumatera Barat Tahun 2019 masih menngunakan pola gerak yang cenderung mengulang-ulang gaya dan bentuk yang lama. Artinya, secara koreologi cenderung tidak berkembang baik. Sementara itu, masih terdapat kecenderungan banyak nomor tarian yang kurang memberi tempat pada para penari perempuan. Suatu kenyataan yang patut disayangkan
\end{abstract}


mengnungat sejarah menunjukkan bahwa justru para koreografer perempuan adalam para pengembang tari Minangkabau kontemporer.

Kata Kunci: FLS2N, Tari Minangkabau, Kajian Kritis, Koreologi, Minangkabau

\section{PENDAHULUAN}

Festival dan Lomba Seni Siswa Nasional (FLS2N) adalah ajang yang selalu dinantikan tingkat sekolah di Indonesia, baik tingkat Sekolah Dasar, Sekolah Menengah Pertama dan Sekolah Menengah atas. Program pemerintah dalam menunjang kreativitas dan bakat peserta didik ini dilaksanakan dalam satu kali dalam setahun, dan setiap tahun diadakan di kota yang berbeda-beda.

Semangat FLS2N disambut dengan antusias di Sumatera Barat, setiap sekolah saling unjuk kebolehan untuk membuktikan siapa yang menjadi terbaik dalah hal kreativitas (Hidayatullah, 2020; Kristanto, 2020; Sinaga, 2016). Persaingan antar sekolah menghasilkan karya yang sangat hebat setiap tahunnya. Persaingan tersebut mengacu kepada kreativitas untuk menunjang nilai edukasi kebudayaan setiap sekolah sehingga melahirkan dan mengembangkan sikap kompetitif, kerjasama dan sportivitas dalam diri siswa yang berwawasan global dan menjalin persahabatan dalam proses melestarikan seni budaya Indonesia (Sinaga et al., 2019; Yuda et al., 2020).

Setiap sekolah di Sumatera Barat sudah menyiapkan anggaran khusus untuk FLS2N. Karya-karya yang berkualitas tentunya membutuhkan pakar atau pelatih yang profesional dalam bidangnya. Pelatih di Sumatera Barat biasanya berasal dari mahasiswa Institut Seni Indonesia Padang Panjang (ISI), Sendratasik UNP dan ada juga dari seniman autodidak yang memang menekuni bidang tersebut.

Tingkat Sekolah Menengah Pertama memiliki lima tangkai cabang lomba yaitu Festival Kreativitas Tari, Musik Tradisional, Gitar Duet, Menyanyi Solo dan Mendesain Poster. Kelima cabang lomba tersebut berhak diikuti oleh setiap siswa yang lolos seleksi dari tingkat sekolah.

Cabang Kreativitas tari adalah salah satu dari kelima cabang tersebut yang paling banyak diminati oleh peserta lomba. Tari sebagai sebuah teks merupakan sesuatu yang bisa dibaca dan di tafsirkan (Sriyadi, 2013). Artinya sebuah tarian yang terlintas di atas panggung bukan sekedar bentuk susunan gerak dan keterampilan teknik atau virtuosity para penari, tetapi dituntut sebuah pendalaman isi, dan itu semua harus sampai pada sasaran atau "makna komunikatif" kepada masyarakat penonton (Hadi \& Penelitian, 2001, p. 9)

Sistem pemilihan penari di sekolah bersifat objektif berdasarkan kemampuan dasar setiap anak, dan pemilihan ini berhak diikuti oleh seluruh siswa aktif baik laki-laki atau perempuan yang masih menduduki bangku kelas VII atau VIII.

Setelah terpilih lima penari yang potensial atau sesuai criteria, maka selanjutnya adalah tugas pelatih untuk mengkonsep garapan sesuai dengan juknis FLS2N tingkat SMP. Proses latihan setidaknya membutuhkan waktu lebih kurang tiga bulan. Mulai dari konsep garapan, musik, kostum, 
properti, rias dan kostum adalah hasil dari buah pikir sang pelatih. Pelatih memiliki tanggung jawab penuh atas apa yang akan ditampilkan nantinya, selain untuk mengharumkan nama sekolah, ini juga ajang bagi para pelatih untuk menunjukkan kualitas dirinya (Sinaga, 2020; Wimbrayardi, 2019; Winangsit, et al., 2017).

Belakangan ini perkembangan cabang tari tingkat SMP selalu menjadi perbincangan di kalangan pelatih, sekolah dan para seniman yang ada di Sumatera barat. Pasalnya muncul sebuah gejolak yang menarik beberapa tahun belakangan ini yaitu, pemenang dalam jangka lima tahun ke belakang dengan memakai penari lakilaki selama berurutan. Hal ini menimbulkan banyak pertanyaan di kalangan para pelatih dan seniman, kenapa peserta sekolah yang memakai penari laki laki selalu memenangkan perlombaan tingkat provinsi di Sumatera Barat? Padahal banyak juga karya yang sangat bagus dengan memakai penari perempuan dan konsep yang matang selalu kandas dalam penjurian tingkat Provinsi. Kalau dikaji berdasarkan garapan dan tekniknya, Perempuan pada tingkat SMP justru lebih bagus bergerak dari lelaki mulai dari kelenturannya, rasa, ekspresi dan faktor lainya mereka lebih menguasai. Hal inilah yang menjadi pertanyaan besar sampai sejauh ini.

Sejarah koreografer dan kepenarian Sumatera Barat tidak memiliki literatur penari pria yang dominan dalam perkembangannya. Karena perempuan Minangkabau mendapat tempat unik dari sudut pandang budaya yang memakai system garis keturunan ibu (matrilineal). Konsep budaya matrilineal ini menawarkan daya tarik bagi posisi perempuan untuk mengembangkan kreativitasnya. Konsep ini lah yang diduga menjadi lahan subur tumbuhnya sikap androginik pada perempuan Minangkabau (Kuardhani, 2000, p. 101). Hal ini tentu saja mempengaruhi Koreografer Minangkabau dalam kehidupan sebagai seniman. Koreografer Minangkabau yang dimaksud yaitu Hoerijah Adam, Gusmiati Suid dan Syofyani Yusaf. Tiga sosok penari dan koreografer perempuan minangkabau ini membuktikan bahwa kepenarian yang kuat atau berkarakter di Minangkabau (Sumatera Barat) dikuasai oleh kaum perempuan. Hal ini turun temurun ke beberapa generasi penerusnya hingga saat ini.

Berdasarkan latar belakang penelitian maka peneliti merumuskan masalah yang akan dikaji yaitu bagaimana kajian kritis penilaian juri dalam lomba FLS2N Tingkat Sekolah Menengah Pertama di Provinsi Sumatera Barat. Penelitian ini bertujuan untuk mengkaji lebih dalam beberapa indikator dalam form penilaian juri terhadap sajian peserta yang menjadi pemenang Cabang Tari tingkat SMP di Provinsi Sumatera Barat.

\section{METODE PENELITIAN}

Penelitian

pendidikan merupakan suatu kegiatan yang diarahkan kepada pengembangan pengetahuan ilmiah tentang kejadiankejadian yang menarik perhatian pendidikan (Manab, 2015). Tujuannya untuk menemukan prinsip-prinsip umum, yaitu penafsiran tingkah laku yang dapat dipakai untuk menerangkan, meramalkan, dan mengendalikan kejadian-kejadian dalam lingkungan pendidikan. 
Pendekatan penelitian yang digunakan adalah deskriptif analitik yang berarti interpretasi terhadap isi dibuat dan disusun secara sistematik/menyeluruh dan sistematis. Data yang diperoleh berupa kata, gambar, atau perilaku tidak dituangkan dalam bilangan atau angka statistik, melainkan tetap dalam bentuk kualitatif yang memiliki arti lebih kaya dari sekadar angka atau frekuensi (Margono, 2005, p. 39).

Informan yang dituju dalam penelitian ini adalah para dewan juri yang aktif dalam beberapa tahun belakangan ini dan juga sekolahsekolah di Kota Padang yang pernah mendapatkan juara di tingkat Provinsi. Informan tersebut adalah Ali Sukri, Koreografer sumbar dan juga dosen tari ISI Padangpanjang, sedangkan untuk juri perwakilan dari kependidikan adalah Indra Yuda, seorang koreografer dan juga dosen di UNP Padang.

Metode pengumpulan data yang digunakan dalam penelitian ini bermacam-macam bentuknya, mulai dari observasi, pengumpulan data, pengambilan dokumentasi terkait tentang pelaksanaan dan pertunjukan waktu perlombaan tingkat provinsi.

Proses analisis data dengan menelaah seluruh data yang tersedia dari berbagai sumber yang telah diperoleh dari penelitian di lapangan, yaitu dari wawancara, pengamatan, dokumen pribadi, dokumen resmi, gambar, foto, dan sebagainya (Moleong dalam Sumaryanto, 2010: 103). Data tentang para pemenang, konsep garapan, pelatih dan guru pendamping. Data peserta yang tidak juara juga diperlukan sebagai perbandingan karya layak atau tidaknya juara ditetapkan berdasarkan juknis.
Hasil analisis data tersebut selanjutnya disusun dalam bentuk laporan dengan teknik deskriptif analisis yaitu dengan cara mendeskripsikan keteranganketerangan atau data-data yang telah terkumpul dan dianalisis berdasarkan teori-teori yang ada.

\section{HASIL DAN PEMBAHASAN}

\subsection{Kajian Kritis Kreativitas Gerak dalam Juknis FLS2N Cabang Tari di Sumatera Barat}

Dalam juknis secara umum disebutkan bahwa indikator penilaian yaitu wiraga, wirama, wirasa dan kepenarian (teknik gerak) dan identitas kedaerahan (gerak, kostum, musik dll), kreativitas dan penyajiannya. Lalu setelah juara ditingkat provinsi akan dilanjutkan pada tingkat nasional. Cenderung ditingkat nasional tim juri tidak mengkaji hal-hal mendasar seperti etika dan estetika kedaerahan namun lebih kepada konsep garap dan relevannya dengan unsur-unsur koreografi sebuah pertunjukan.

Pada dasarnya penunjang sebuah karya tari dalam event FLS2N bukanlah pada Gendernya, tapi berdasarkan pemahaman sebagai berikut :

\section{a. Wirama, Wiraga dan Wirasa}

Wirama adalah sebuah kepekaan terhadap irama atau music pengiring tari. Ini menjadi sebuah kekuatan untuk menyesuaikan tempo penari dengan musik iringan. Wirama menjadi penilaian utama untuk kepekaan peserta tari, pemahaman akan musik harus ditanamkan pada peserta didik sehingga nanti ketika tampil ada kesesuaian antara gerakan dengan music yang melahirkan sebuah 
perpaduan yang enak dilihat.

Wiraga diartikan juga sebagai maksimal atau totalitas dalam bergerak. Keseriusan peserta tari dilihat dari teknik kepenarian yang ditanamkan pada peserta didik. Untuk melatih basic kepenarian anak SMP memang membutuhkan kesabaran dan teknik mengajar. Mempunyai teknik yang bagus tentu tidak cukup sampai di sana, stamina dan ketahanan tubuh juga menjadi penunjang untuk membuat penari terlihat fit ketika mendemonstrasikan gerak yang telah dilatih selama ini.

Wirasa adalah kesadaran untuk mengolah rasa dalam mengaplikasikan gerak yang dihadirkan. Tanpa rasa, penari tidak ubahnya seperti seorang yang sedang senam. Rasa dalam pengertian ini memiliki perang utama dalam mewujudkan wirama dan wiraga. Tanpa wirasa, sebuah pertunjukan tari seperti kehilangan nyawa atau bisa dikatakan tidak memiliki jiwa.

\section{b. Identitas Kedaerahan (Budaya Lokal)}

Mengembangkan budaya lokal menjadi sasaran utama dalam juknis setiap tahunnya, meski kelihatan sederhana namun sebenarnya sulit untuk mengaplikasikan identitas daerah. Pemahaman pelatih selalu mengusung gaya kekinian sehingga justru keinginan yang terlalu akrobatik membuat terkikisnya nilai budaya lokal yang menghilangkan identitas daerah itu sendiri.

\section{c. Kreativitas Garapan}

Kreativitas garapan meliputi gerak, tata rias busana, property, pola lantai dan desain dramatik tari. Halhal ini menentukan bagus tidaknya sebuah karya tari. Minimnya kreativitas membuat tari itu tidak bisa dinikmati karena tidak ada unsure kebaruannya. Pengolahan properti bisa memberikan warna dalam garapan sehingga melahirkan hal-hal tak terduga. Property juga diiringi oleh penggarapan pola lantai agar terjadi satu kesatuan dalam membangun dramatik tari.

\section{d. Penyajian}

Penyajian meliputi harmoni, keutuhan dan kekompakan. Penilaian terakhir ini menentukan sejauh mana proses yang dilakukan untuk sampai terselenggaranya lomba. Pelatih dituntut untuk menyamaratakan kemampuan penari sehingga tidak ada satu atau dua penari yang tidak cukup mengiringi kemampuan penari lainnya.

Sebagai upaya untuk memahami perspektif juri sebagai kunci dalam menilai pemenang, peneliti mewawancarai dua orang juri yang merupakan wakil dari akademisi sekaligus koreografer di Sumatera Barat. Perspektif juri dalam menilai tentang gender pada FLS2N Kreativitas Tari menurut Indrayuda, seorang koreografer dan dosen di Sendratasik UNP Padang, dia mengatakan bahwa:

"Secara power, gestur, kelenturan dan teknik menari lebih dikuasai perempuan di banding lakilaki, karena secara ketubuhan perempuan lbh mudah dibentuk dan diolah menjadi teknik yang estetis dan artistik. Secara kekuatan dan kecepatan tetap saja laki-laki lebih mnguasai itu ketimbang perempuan. Filosofi di minangkabau tari tradisi dan tari kreasi berpijak pada gerak silat sehingga pengembangan gerak tari dominan di olah oleh perempuan 
dengan nilai2 kebaruannya yang terkait dengan artistik sebuah karya tari berdasarkan estetika tapi tdk dominan mengkaji etika. Tari minang bersumber atau berpijak dari gerak silat yang terkandung di dalamnya seperti: kewaspadaan, ketangkasan, ketajaman, ketegasan dan demonstratif. Sehingga karakter yang dimunculkan oleh penari perempuan akan terbawa/tetap terlihat gaya laki2 secara power penari perempuan. hanya saja kesesuaian konsep, tema dan penyajian tari secara keutuhannya menjadi unsur utama dalam penilaian. Karena gerak yang dianggap kurang estetis belum tentu tidak etis" (Indrayuda, 2020).

LEMBAR PENILAIAN KREATIVITAS TARI FESTIVAL DAN LOMBA SENI SISWA NASIONAL (FLS2N)

\begin{tabular}{|l|l|l|l|}
\hline \multirow{2}{*}{ NO } & JUDUL & \multirow{2}{*}{ ASPEK YANG DINILA \& BOBOT } & SKOR \\
\cline { 4 - 4 } & & $\mathbf{( 6 0 - 9 0 )}$ \\
\hline 1 & & Kepenarian $(35 \%)$ & \\
\hline & & Identitas kedaerahan $(20 \%)$ & \\
\hline & & Kreativitas (25\%) & \\
\hline & & Penyajan (20\%) & \\
\hline
\end{tabular}

Gambar 1. Indikator Penilaian dan Kriteria Juri dalam Juknis FLS2N Kreativitas Tari Tahun 2019

(Sumber: Kemendikbud, 2019)

Sedangkan pendapat lain tentang gender dalam FLS2N Tari ditanggapi oleh Ali Sukri, seorang koreografer dan Dosen Tari di ISI Padangpanjang, dia mengatakan bahwa: "Tidak aspek dalam Tari mengenai sumbang duo baleh. Indikator menilai lebih kepada konsep, tema, teknik gerak dan kesesuaian dalam garapannya. Jika sumbang duo baleh menjadi sebuah pertimbangan dalam tari maka secara kreativitas akan terbatas." (Ali Sukri, 2020)

Terdapat sedikit perbedaan antara koreografer yang berasal dari akademisi kependidikan dan kesenimanan, karakter ini tentu saja sangat melekat dan memberikan perspektif yang berbeda dari masingmasing juri, namun hal ini seharusnya tidak membatasi juri dalam memahami dan melaksanakan juknis pada setiap tangkai lomba di FLS2N.

\subsection{Analisis Konsep Sajian Pemenang FLS2N Cabang Tari Tingkat SMP Provinsi Sumatera Barat Tahun 2019}

Tema tari FLS2N pada tahun 2019 adalah Kepahlawanan, Tema ini menggambarkan perjungan masyarakat ataupun tokoh (pahlawan nasional, pahlawan daerah, pahlawan masa kini) yang berjasa dalam membangun bangsa, menegakkan kebenaran dan keadilan serta memperjuangkan kesejahteraan masyarakat. Adapun materi yang ditampilkan adalah garapan tari kelompok bik dalam bentuk drama tari (bercerita) maupun dramatik tidak bercerita. Durasi penyajian 7-9 menit peserta yang mengikuti kegiatan ini mewakili sekolah dengan jumlah penari 5 orang (putra semua, putri semua dan gabungan putra dan putri). Karya tari merupakan hasil dari kreativitas siswa yang didampingi oleh guru/pelatih. Karya tari yang dilombakan dalam event ini bersifat orisinalitas, garapan baru yang sesuai dengan tema dan didukung dengan musik iringan yang menggunakan unsur musik tradisi budaya setempat.

Kriteria juri sesuai dengan juknis nasional harus memiliki wawasan mengenai tari daerah setempat, memiliki kepekaan estetis dan pengetahuan perkembangan tari di Indonesia, memiliki kompetensi di bidang koreografi dan bersifat adil dan netral. Aspek dari pengamatan 
tari, meliputi wiraga wirama dan wirasa, identitas kedaerahan, kreativitas garapan, kostum, rias, properti, pola lantai, tata pentas, desain dan dramatik. Penyajian harmoni, keutuhan dan kekompakkan. Penilaian dengan menggunakan sistem skor berdasarkan point di atas.

Berdasarkan pengamatan menarik yang terjadi pada perlombaan cabang tari tingkat smp pada tahun 2019. Sebuah garapan karya tari dengan didukung 5 penari laki-laki yang sangat memukau dan energik yang terinspirasi dari kisah pahlawan tan malaka. Jika dikaji lebih dalam mengenai elemen dasar koreografi tidak dapat terlepas antara kesatuan elemen-elemen komposisi tari yaitu ruang, waktu dan tenaga.

Prinsip-prinsip pembentukan gerak tari itu menjadi konsep penting dalam koreografi. Gerak dalam koreografi adalah bahasa yang dibentuk menjadi pola-pola gerak dari seorang penari yang dinamis, artinya tidak hanya serangkaian gerak yang dihubung-hubungkan tetapi terdiri dari gerak yang kontinyu. Indikator dalam gerak terdiri dari Ruang, (ruang gerak dan ruang tempat bergerak/pentas). Ruang gerak meliputi, arah hadap, volume, level, garis. Elemen koreografi memiliki hubungan dengan bentuk gerak (design of movement) yang dipahami sebgai struktur ritmis dari pola gerak dengan membentuk aspke ruang sehingga menjadi hidup sebagai elemen estetis dalam koreografi. Waktu sebagai faktor pengorganisir dalam setiap gerak tari sebagai suatu alat yang memperkuat hubungan kekuatan rangkaian gerak sehingga menambah keteraturan struktur tari. sedangkan tenaga membahas tentang kualitas, intensitas dan aksen. Tentu saja elemen-elemen tari merupakan dasar dalam sebuah komposisi untuk mewujudkan garapan tari yang menjadi satu kesatuan yang komunikatif secara baik.

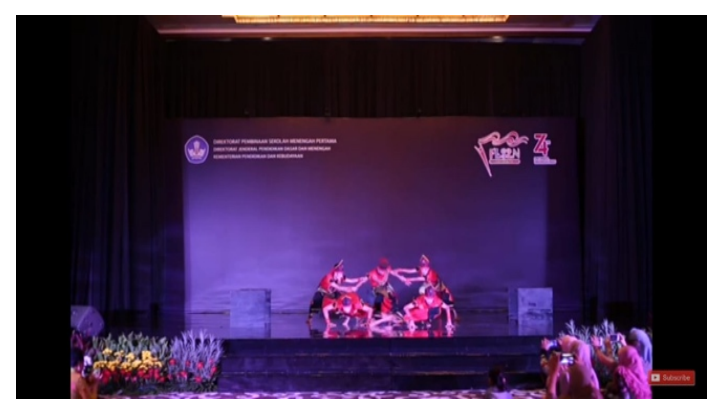

Gambar 2. SMP N 1 Kec Payakumbuh Kab. Lima Puluh Kota - Pemenang Lomba Kreativitas Tari FLS2N 2019 Tingkat Provinsi Sumatera Barat

Munculnya sebuah persoalan yang nampak pada garapan karya tari dalam event FLS2N berdasarkan kajian koreografinya yang dilihat dari elemen tari ruang waktu dan tenaga. Pada pemenang tingkat smp tahun 2019, terdapat beberapa hal yang harus diperhatikan sebagai piñata tari/koreografer mengenai ruang waktu dan tenaga. Secara kepenarian dapat di apresiasi bahwa penari dalam garapan karya ini memiliki teknik kepenarian yang bagus dan maksimal secara gerak dan mampu mengaplikasikan konsep tari, identitas kedaerah dengan kostum yang digunakan yaitu galembong, pijakan gerak tari dari bentuk-bentuk bunga silat, serta dendang/vocal music yang dilahirkan unsur-unsur tradisi di Minangkabau. Kreativitas, secara konsep, karya ini telah di interpretasikan ke dalam bentuk baru baik dalam property, desain dan dramatik cerita merupakan imajinasi piñata tari sehingga terciptalah sebuah karya yang kreatif dan inovatif. Keutuhan, pada dasarnya tentu saja 
pengamatan secara keseluruhan karya tari yang dipentaskan yang pastinya tidak terlepas dari dasar komposisi into sendiri seperti yang di bahas di atas.

$\begin{array}{ccr}\text { Aspek } & \text { koreografi } & \text { secara } \\ \text { keseluruhan } & \text { adanya } & \text { ketidak }\end{array}$ seimbangan dalam gerak yang dilakukan, keseimbangan di sini dapat dilihat dari ruang gerak yang dominan menggunakan ruang gerak yang besar, sehingga bentuk geraknya kurang bervariasi sementara ada beberapa peristiwa dalam karya ini yang bisa mengkombinasi ruang-ruang gerak tubuh. Selain itu, koreografer dalam garapan ini tidak membagi power/tenaga yang digunakan penari sehingga terlihat dari awal sampai akhir menggunakan tenaga maksimal yang mengakibatkan kelelahan dalam pertunjukan berlangsung, penari sesak nafas karena tidak mampu mengontrol kekuatan dalam setiap gerak. Ini di akibatkan dominan menggunakan intensitas gerak yang kuat dan ruang yang besar. Sebaiknya dalam menata sebuah komposisi tari peñata tari harus mempertimbangkan stamina penari dan penataan gerak yang telah distilirisasi melalui indikator dalam gerak dan pembagian suasana agar tidak terkesan keras dari awal sampai akhir (ekstrim) karena koreografi itu sendiri yang kita pahami yaitu kebebasan kreatif bahkan unik dan aneh tetapi masih dalam konteks dasar estetika gerak tari.

\subsection{Analisis Gerak dan Konsep Peserta FLS2N Kreativitas Tari 2019}

Pengamatan secara umum lomba cabang tari FLS2N di wilayah provinsi sumatera barat. Dikaji dari unsurunsur gerak yang menjadi pola penting dalam koreografi, adanya pola yang secara seluruhan peserta lomba dari beberapa kota kabupaten, memiliki kesamaan untuk pola garap. Hal ini terjadi dari beberapa tahun sebelumnya pemenang lomba tari ditingkat provinsi selalu menang dengan gerak-gerak yang cepat tempo yang cepat, ruang gerak besar bentuk yang tajam dan tegas. Ini menjadi sebuah acuan oleh setiap pelatih/koreografer tari fLS2N untuk menggarap karya tari yang kecepatannya cepat agar terlihat kesulitan yang tinggi dalam pemilihan gerak. Namun tanpa disadari sesunguhnya capaian karya tari untuk lomba kurang memperhatikan indikator-indikator yang terdapat dalam gerak karena lebih mengutamakan ekstrimnya dari pola gerak dengan bentuk yang kuat baik karya tari yang didukung dengan penari laki-laki atau bahkan penari perempuan. Karena di anggap karya yang baik dengan teknik yang baik, adalah penari yang mampu bergerak cepat dan tegas sehingga terkadang ruang gerak tubuh penari sesungguhnya tidak terlihat secara maksimal garis-garis gerak penari, sebab lebih kepada menyesuaikan tempo atau ritme yang dibangun dengan musik pengiring tari yang tentu saja penyesuaian dari keinginan sang koreografer.

Persoalan ini di amati sejak 3 tahun kebelakang, karena memang kebetulan yang juara secara koreografi hampir kesetiap tahunnya berpola sama. Mulia dari awal penampilan dibuka dengan gerak yang cepat, music yang keras dan setelahnya akan ada pergantian suasana yang dengan music atu tempo pelan yang dipola seketika setelah itu hingga selesai kembali pada gerak 
yang tajam, tegas, cepat. Hal ini juga menjadi bahan referensi bagi setiap koreografer atau pelatih tari sehingga ketika dalam ajang perlombaan hampir seluruh karya dalam bentuk pola garap atau struktur garapnya memiliki kesamaan. Hanya saja bisa di lihat dari kesempurnaan karya dengan kualitas gerak dan proses akan terbaca dengan hasil penampilannya meskipun secara pola garapa sama.

Selain itu pola gerak yang dipakai dalam cabang tari fls2n wilayah provinsi sumbar merata banyak memakai gerak-gerak tusuak karena ketajaman mudah diperjelas dengan bentuk jari yang merapat dan menusuk kearah (kiri/kanan, diaogonal dsb) dalam postur tubuh yang tegap, kaki membentuk pitunggua dengan bermainan segmensegmen tubuh dan lebih dominan aksen kepala untuk menunjang kekuatan dalam setiap pergerakan. Tapi ada juga yang mengacu pada pola ini namun kapasitas penarinya tidak mampu dalam melakukan seperti tersebut.

Jadi kurang adanya pembaruan dalam unsur garap karya tari pada event FLS2N ini karena selalu dengan pola yang sama, secara kreativitas untuk menciptakan inovasi-inovasi justru mulai berkurang meskipun secara konsep koreograferkoreografer muda asal Minangkabau memang memiliki ide / pola pikir yang sangat berbeda berdasarkan lingkungan dan budaya-budaya yang terkadang mulai lupa dan penata mampu untuk menjadikan sebuah dasar inspirasi yang dituangkan ke dalam bentuk karya tari.

Hampir secara keseluruhan peserta memiliki konsep yang menarik dan unik. Musik pendukung sangat kreatif mengikuti tema tarian. geraknya kreatif dan inovatif. teknik kepenarian bagus, hanya pola garapannya hampir sama untuk seluruh peserta, gerak juga hampir sama, setiap kali lomba kita merasa melihat gerak-gerak dari sebelumnya, itu bisa saja disebabkan kurangnya eksplorasi sehingga selalu karena lebih mengacu pada pemenang dari tahun sebelumnya.

\section{KESIMPULAN}

Kesimpulan yang dapat diambil dari pembahasan di atas adalah konsep sajian setiap peserta menjadi sebuah perbincangan selama 3 tahun terakhir dalam konteks FLS2N cabang Kreativitas Tari. Hal tersebut dibuktikan dengan peserta pria yang selalu menjadi juara 1 pada tingkat provinsi dan lanjut ke nasional mewakili Sumatera Barat.

Beberapa aturan tentang perempuan di Minangkabau seperti sumbang duo baleh diyakini menjadi salah satu faktor utama dalam pembahasan gender. Beberapa Juri dirasa menghilangkan karakter atau membunuh potensi penari perempuan Minang, karena aturan tatanan kehidupan perempuan di Minangkabau dikaitkan ke dalam bentuk karya seni tari sehingga nilainilai yang dianggap janggal/ sumbang menjadi patokan dalam menilai karya tari. Sementara koreografer pendobrak tari di Minangkabau itu perempuan. Sebagai contoh salah satu kuda-kuda gerak atau pitunggua merupakan dasar dalam tari minang, sementara juri dari kalangan pendidik seni lebih menyukai pola gerak perempuan yang feminim. Kunci utama yang menjadi indikator dalam sebuah perlombaan tari harusnya lebih mengacu kepada wiraga, wirasa, wirama dan beberapa unsur lain 
seperti Identitas Kedaerahan, Kreativitas Garapan, dan Penyajian Tari secara utuh meskipun harus tetap memuat nilai, etika dan estetika dari masing-masing daerah.

\section{DAFTAR PUSTAKA}

Hadi, Y. S., \& Penelitian, I. S. I. Y. L. (2001). Pasang surut tari klasik gaya Yogyakarta: pembentukan, perkembangan, mobilitas. Lembaga Penelitian, Institut Seni Indonesia Yogyakarta.

Hidayatullah, R. (2020). Kreativitas Dalam Pendidikan Musik: Berpikir Divergen Dan Konvergen. Musikolastika: Jurnal Pertunjukan Dan Pendidikan Musik 2(1), 1-7.

Kristanto, A. (2020). Urgensi Kearifan Lokal melalui Musik Gamelan dalam Konteks Pendidikan Seni di Era 4.0. Musikolastika: Jurnal Pertunjukan Dan Pendidikan Musik, 2(1), 5158.

Kuardhani, H. (2000). Teater rakyat janger Banyuwangi ungkapan keberadaan masyarakat pendukungnya. [Yogyakarta]: Universitas Gadjah Mada.

Manab, H. A. (2015). Penelitian Pendidikan Pendekatan Kualitatif. Jakarta: Kalimedia.

Margono, S. (2005). Metodologi penelitian pendidikan. Jakarta: Rineka Cipta.

Sinaga, F. S. S. (2020). Musik Trunthung Sebagai Wujud Kearifan Lokal Dalam Konteks Pendidikan Seni. Tonika: Jurnal Penelitian Dan
Pengkajian Seni, 3 (1), 27-38.

Sinaga, F. S. S. (2016). Musik Trunthung Sebagai Media Ekspresi Masyarakat Warangan. Seminar Antar Bangsa, 161-174. https://doi.org/10.31227/osf. io/wc4vy

Sinaga, F. S. S., Maestro, E., Winangsit, E., \& Yensharti, Y. (2019, March). Learning and Singing: Thematic Children Songs in Kindergarten. Seventh International Conference on Languages and Arts (ICLA 2018). https://www.atlantispress.com/article/55914484

Sriyadi, S. (2013). Sanggar Tari Sebagai Patner Dalam Pendidikan Sekolah Kejuruan Tari. Abdi Seni, 5(1).

Wimbrayardi, W. (2019). Musik Tradisi Sebagai Salah Satu Sumber Pengembangan Karya Cipta. Musikolastika: Jurnal Pertunjukan Dan Pendidikan Musik, 1(1), 7-12.

Winangsit, E., Ganap, V., \& Erimurti, K. (2017). Musik Gambang Semarang Garapan Paguyuban Kesenian Otty Panoedjoe Di Balemong Resort Ungaran. Universitas Gadjah Mada.

Yuda, F., Winangsit, E., Hidayat, H. A., \& Sinaga, F. S. S. (2020). Limited Creativity as a Form of Minangkabau Traditional Randai Preservation. Eighth International Conference on Languages and Arts (ICLA2019), 379-383. 